\title{
Glycated Hemoglobin, Body Weight and Blood Pressure in Type 2 Diabetes Patients Initiating Dapagliflozin Treatment in Primary Care: A Retrospective Study
}

John Wilding · Clifford Bailey • Una Rigney · Betina Blak •

Wendy Beekman · Cathy Emmas

Received: June 30, 2016 / Published online: September 1, 2016

(C) The Author(s) 2016. This article is published with open access at Springerlink.com

\section{ABSTRACT}

Introduction: The present study aimed to describe characteristics of patients with type 2 diabetes (T2D) in UK primary care initiated on dapagliflozin, post-dapagliflozin changes in glycated hemoglobin $\left(\mathrm{HbA}_{1 \mathrm{c}}\right)$, body weight and blood pressure, and reasons for adding dapagliflozin to insulin.

Enhanced content To view enhanced content for this article go to http://www.medengine.com/Redeem/ C885F0604F94A707.

Electronic supplementary material The online version of this article (doi:10.1007/s13300-016-0193-8) contains supplementary material, which is available to authorized users.

J. Wilding $(\bowtie)$

Diabetes and Endocrinology Research Group, Institute of Ageing and Chronic Disease, Clinical

Sciences Centre, University Hospital Aintree,

Liverpool, UK

e-mail: j.p.h.wilding@liv.ac.uk

C. Bailey

Life and Health Sciences, Aston University,

Birmingham, UK

U. Rigney · B. Blak · C. Emmas

AstraZeneca, 600 Capability Green, Luton, UK

W. Beekman

AstraZeneca, Louis Pasteurlaan 5, 2719 EE

Zoetermeer, The Netherlands
Methods: Retrospective study of patients with T2D in the Clinical Practice Research Datalink with first prescription for dapagliflozin. Patients were included in the study if they: (1) had a first prescription for dapagliflozin between November 2012 and September 2014; (2) had a Read code for T2D; (3) were registered with a practice for at least 6 months before starting dapagliflozin; and (4) remained registered for at least 3 months after initiation. A questionnaire ascertained reason(s) for adding dapagliflozin to insulin.

Results: Dapagliflozin was most often used as triple therapy $(27.7 \%)$, dual therapy with metformin (25.1\%) or added to insulin (19.2\%). Median therapy duration was 329 days $[95 \%$ confidence interval (CI) 302-361]. Poor glycemic control was the reason for dapagliflozin initiation for $93.1 \%$ of insulin-treated patients. Avoiding increases in weight/body mass index and insulin resistance were the commonest reasons for selecting dapagliflozin versus intensifying insulin. $\mathrm{HbA}_{1 \mathrm{c}}$ declined by mean of $9.7 \mathrm{mmol} / \mathrm{mol}$ (95\% CI 8.5-10.9) (0.89\%) 14-90 days after starting dapagliflozin, $10.2 \mathrm{mmol} / \mathrm{mol}$ (95\% CI 8.9-11.5) (0.93\%) after $91-180$ days and 
$12.6 \mathrm{mmol} / \mathrm{mol} \quad(95 \%$ CI $11.0-14.3) \quad(1.16 \%)$ beyond 180 days. Weight declined by mean of $2.6 \mathrm{~kg}$ (95\% CI 2.3-2.9) after 14-90 days, $4.3 \mathrm{~kg}$ (95\% CI 3.8-4.7) after 91-180 days and $4.6 \mathrm{~kg}$ (95\% CI 4.0-5.2) beyond 180 days. In patients with measurements between 14 and 90 days after starting dapagliflozin, systolic and diastolic blood pressure decreased by means of 4.5 (95\% CI -5.8 to -3.2$)$ and 2.0 (95\% CI -2.9 to -1.2$) \mathrm{mmHg}$, respectively from baseline. Similar reductions in systolic and diastolic blood pressure were observed after 91-180 days and when follow-up extended beyond 180 days. Results were consistent across subgroups.

Conclusion: $\mathrm{HbA}_{1 \mathrm{c}}$, body weight and blood pressure were reduced after initiation of dapagliflozin in patients with T2D in UK primary care and the changes were consistent with randomized clinical trials.

Funding: AstraZeneca.

Keywords: Blood pressure; Body weight; Dapagliflozin; Diabetes; Glycated hemoglobin; HbA1c

\section{INTRODUCTION}

Dapagliflozin, a selective sodium-glucose co-transporter-2 inhibitor, reduces renal glucose reabsorption, resulting in glycosuria, improved glucose control, weight reduction and blood pressure [1]. Placebo-controlled randomized clinical trials (RCTs) and comparator studies have shown that dapagliflozin is effective in treatment-naïve patients with type 2 diabetes (T2D) [2, 3] as well as add-on therapy for patients with inadequate glycemic control while taking metformin [1, 4-6], sitagliptin (with or without metformin) [7], sulphonylurea (with or without metformin) $[8,9]$ and insulin $[10]$.
Dapagliflozin shows similar efficacy when used as dual therapy with metformin or insulin, and in triple therapy with other oral glucose-lowering drugs [1, 4-8, 10, 11].

However, clinical trials are not necessarily representative of the patient population treated in routine care. For example, up to $39 \%$ of T2D patients are ineligible based on age alone for trials that have the most stringent inclusion and exclusion criteria [12]. Observational studies with minimal eligibility criteria allow the assessment of use and outcomes in the wider population and have stronger external validity. This observational study aimed to describe the characteristics of patients with T2D in primary care in the UK who received their first prescription for dapagliflozin. The study also aimed to quantify the changes in glycated hemoglobin $\left(\mathrm{HbA}_{1 \mathrm{c}}\right)$, body weight and blood pressure in patients after being initiated on dapagliflozin and sought information on the clinical reasons why the prescriber added dapagliflozin to insulin and resulting changes in insulin dose.

\section{METHODS}

The patient data for this retrospective observational study were obtained from the Clinical Practice Research Datalink (CPRD), which contains anonymized longitudinal patient records collected from more than 12 million patients across the UK [13]. Patients were included in the study if they: (1) had a first prescription for dapagliflozin between November 2012 and September 2014; (2) had a Read code for T2D (Supplementary material S1); (3) were registered with a practice for at least 6 months before starting dapagliflozin; and (4) remained registered for at least 3 months after initiation. A questionnaire (Supplementary 
material S2) was sent to the general practices of the subset of patients prescribed dapagliflozin as add-on to insulin to ascertain the clinical reason for prescribing dapagliflozin and the dose of insulin before and after dapagliflozin initiation.

\section{Statistical Methods}

Eligible data were analyzed using descriptive statistics. Changes in $\mathrm{HbA}_{1 \mathrm{c}}$, body weight and systolic and diastolic blood pressure were analyzed for those patients with a measurement before receiving dapagliflozin and at least one measurement during the year after the first dapagliflozin prescription. Results were grouped by time since dapagliflozin initiation: 14-90 days; 91-180 days; and $>180$ days (up to 365 days).

Baseline characteristics and follow-up variables were described by frequency and percentage distributions. Continuous and count variables were given using mean [ \pm standard deviation (SD)], median (quartiles) and $95 \%$ confidence intervals (CIs). All analyses were performed using SAS version 9.2 (SAS Institute, Inc., Cary, NC, USA).

Logistic regression models (reporting Odds Ratios, ORs) were used to examine patient characteristics associated with weight change and achieving $\mathrm{HbA}_{1 \mathrm{C}}$ targets. The model included only measures recorded 14-365 days after dapagliflozin initiation while patients were on treatment. If patients had more than one measure after dapagliflozin initiation, only the first was examined.

\section{Compliance with Ethics Guidelines}

This was an observational, retrospective study using anonymized data from CPRD, which holds ethical approval for observational studies. The Independent Scientific Advisory Committee for Medicines and Healthcare products Regulatory Agency (Protocol Number 14_236AMn) approved this study.

This article is based on observational data and does not involve any new studies of human or animal subjects performed by any of the authors.

\section{RESULTS}

\section{Patient Characteristics}

Of 2401 patients who received at least one prescription for dapagliflozin in the study period, 1732 fulfilled the inclusion criteria with sufficient follow-up ( $\geq 3$ months) to enable description of co-prescribed medicines (Fig. 1). $\mathrm{HbA}_{1 \mathrm{c}}$ values were recorded for 1091 patients, body weight was recorded in 970 and blood pressure in 851 patients before the first prescription of dapagliflozin and during dapagliflozin treatment.

The mean age of the patients (57.9\% male) included in the analysis was 57.5 (SD 10.5) years (Table 1). At baseline, mean $\mathrm{HbA}_{1 \mathrm{c}}$ was 80.1 (SD 17.9) $\mathrm{mmol} / \mathrm{mol}(9.5 \%)$ and the mean weight was 103.1 (SD 22.9) $\mathrm{kg}$. The mean time since T2D diagnosis was 9.5 (SD 6.0) years and 36.9\% of patients had a history of retinopathy, $20.4 \%$ a history of neuropathy and $9.8 \%$ a history of nephropathy.

\section{Dapagliflozin Treatment}

Within the first 3 months after initiation, dapagliflozin was most commonly used as triple therapy with other oral glucose-lowering drugs $(27.7 \%$ of dapagliflozin users), as dual therapy with metformin $(25.1 \%)$, or added to 


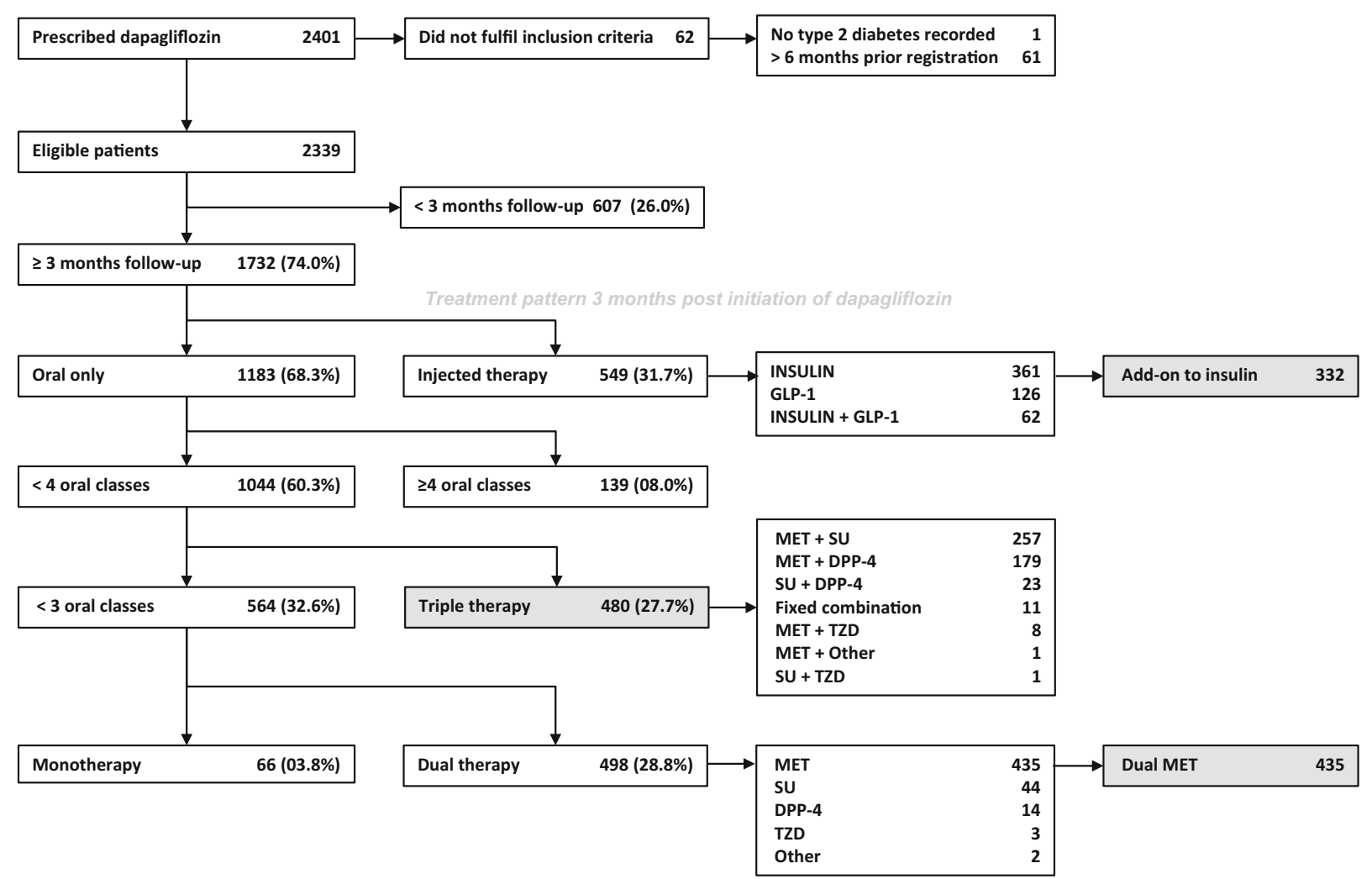

Fig. 1 Disposition of patients. Met metformin, $S U$ sulphonylurea, DPP-4 dipeptiyl peptidase 4 inhibitor, TZD thiazolidlnedione, GLP-1 glucagon-like peptide 1 receptor agonist

insulin (19.2\%) (Fig. 1). In the 3 months, before the first prescription for dapagliflozin, a wide range of other oral diabetes medicines was prescribed (Table 1). In patients who received triple therapy (not shown in table), the most common prior treatments were: metformin and a dipeptidyl peptidase-4 (DPP-4) inhibitor $(21.5 \%)$; metformin and sulphonylurea (19.8\%); or metformin, sulphonylurea and DPP-4 inhibitor (20.6\%). In patients who received dual therapy, the most common prior treatments were: metformin monotherapy (43.9\%); metformin and DPP-4 inhibitor $(19.8 \%) ;$ or metformin and sulphonylurea (11.7\%). Most patients were initiated on $10 \mathrm{mg}$ dapagliflozin $(86.1 \%)$, the remainder on $5 \mathrm{mg}$; median duration of therapy was 10.8 months (329.0 days; 95\% CI 302.0-361.0).

\section{Reasons for Adding Dapagliflozin to Insulin}

Additional information was requested from the general practices for 217 patients who received dapagliflozin as add-on to insulin. Of these, 145 questionnaires included some responses $(66.8 \%$ response rate), 23 questionnaires were returned with no data, and 49 questionnaires were not returned.

For most patients on insulin $(93.1 \%)$, the general practitioner (GP) reported that poor glycemic control was the reason for dapagliflozin initiation, with 131 requiring $\mathrm{HbA}_{1 \mathrm{c}}$ improvement, 35 fasting glucose level improvement and 23 post-prandial glucose level improvement at dapagliflozin initiation. GPs reported more than one glycemic parameter for 40 patients. 


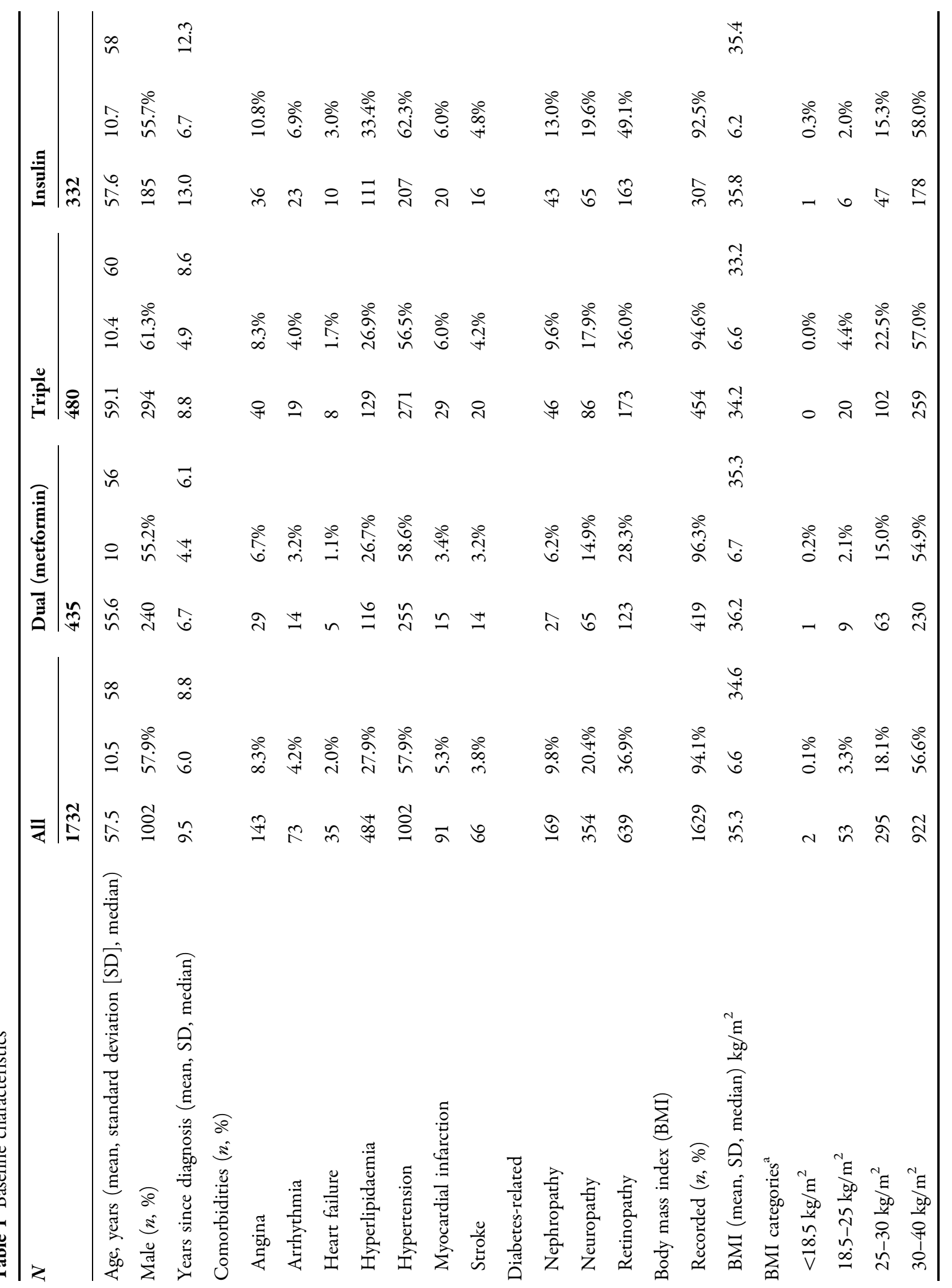




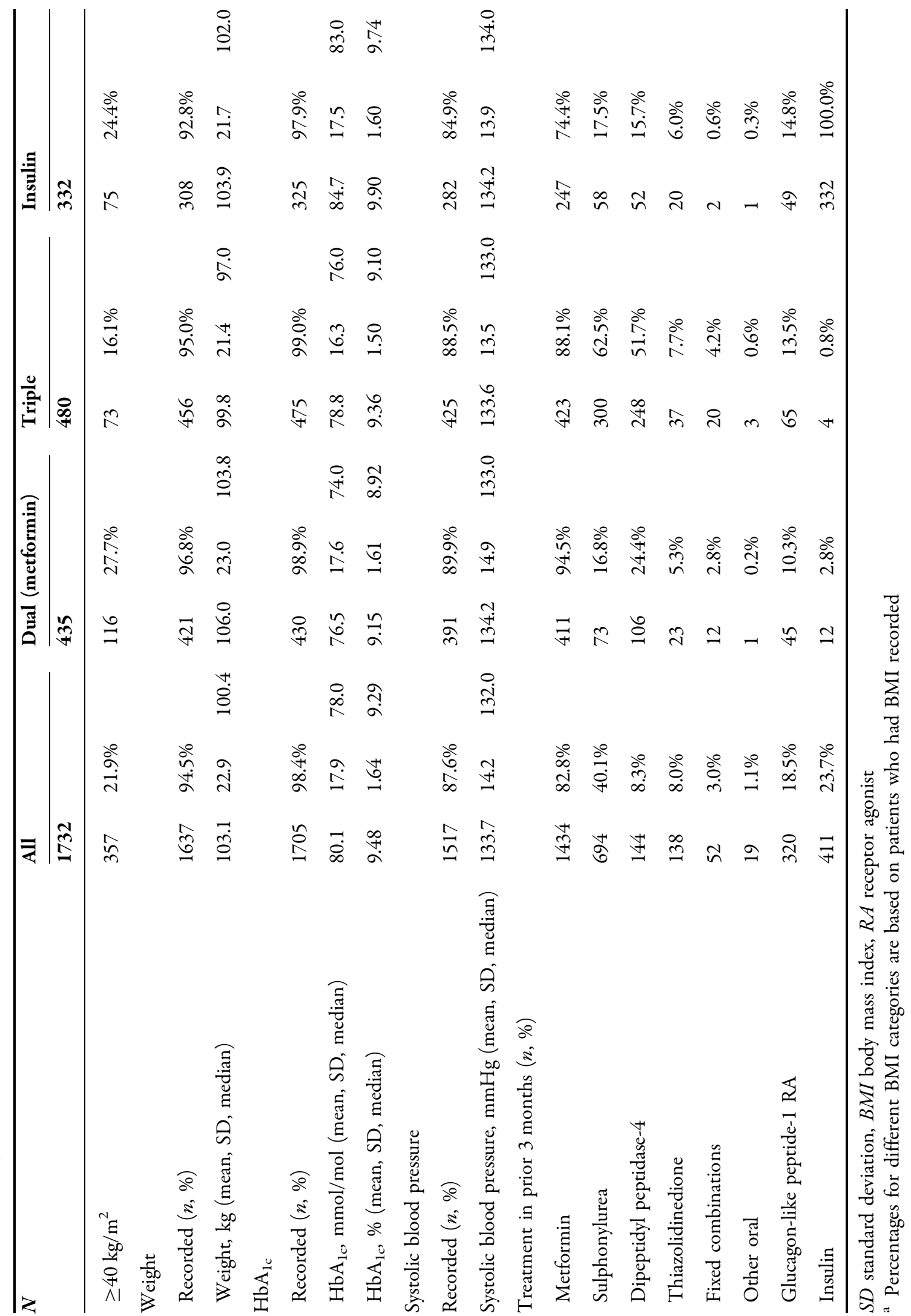




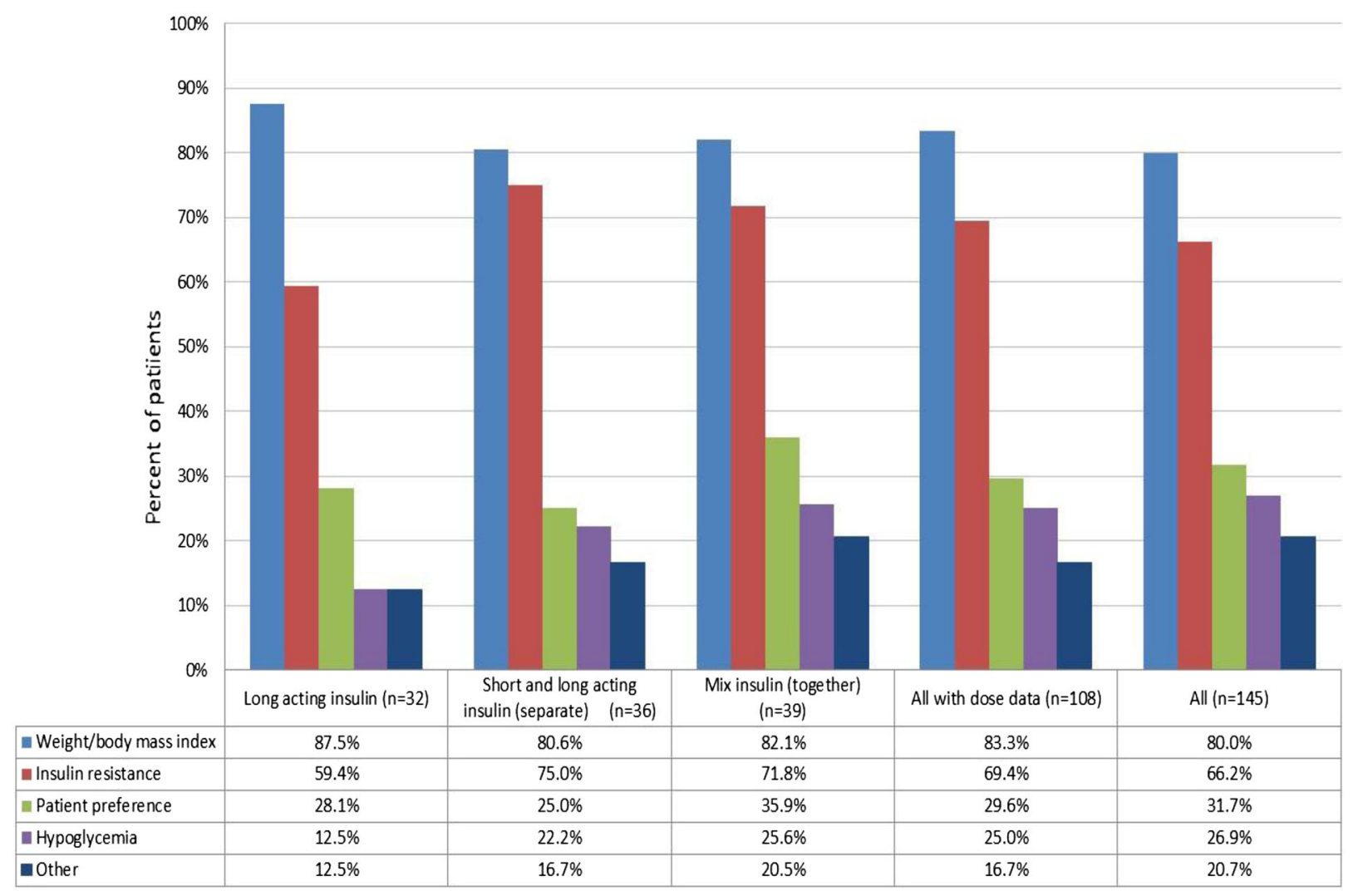

Fig. 2 Reasons for use of dapagliflozin with insulin other than more/maximal intensification

Avoiding increases in weight or body mass index (BMI) $(n=116 ; 80.0 \%)$ and insulin resistance $(n=96 ; 66.2 \%)$ were the most commonly recorded reasons for selecting dapagliflozin instead of intensifying insulin treatment to achieve better glycemic control. Reasons also included: patient choice $(n=46$; $31.7 \%)$; risk of hypoglycemia $(n=39 ; 26.9 \%)$; and other reasons $(n=37 ; 20.7 \%)$, of which approximately half were other clinician's decision $(n=18)$ (Fig. 2).

\section{Change in $\mathrm{HbA}_{1 \mathrm{c}}$ Following Initiation of Dapagliflozin}

In patients with a recorded measurement, mean $\mathrm{HbA}_{1 \mathrm{c}}$ was lowered by $9.7 \mathrm{mmol} / \mathrm{mol}(95 \% \mathrm{CI}$ $8.5-10.9) \quad[0.89 \% \quad(95 \% \quad$ CI $\quad 0.78-0.99)]$ 14-90 days after starting dapagliflozin,
$10.2 \mathrm{mmol} / \mathrm{mol} \quad(95 \%$ CI $\quad 8.9-11.5) \quad[0.93 \%$ (95\% CI 0.81-1.05)] after 91-180 days and $12.6 \mathrm{mmol} / \mathrm{mol}$ (95\% CI $11.0-14.3)$ [1.16\% (95\% CI 1.01-1.31)] beyond day 180 (Fig. 3a; Supplementary material S3). This pattern of greater reduction of $\mathrm{HbA}_{1 \mathrm{c}}$ with longer treatment was seen in most treatment subgroups. Patients in the upper tertile of baseline $\mathrm{HbA}_{1 \mathrm{c}}$ (baseline $\geq 85 \mathrm{mmol} / \mathrm{mol}$ ) showed a greater reduction in $\mathrm{HbA}_{1 \mathrm{c}}$ [ $-17.7 \mathrm{mmol} / \mathrm{mol}$ (95\% CI -20.1 to -15.4$)$; $-1.62 \%(95 \% \mathrm{CI}-1.84$ to -1.41$)]$ than those with the lower tertile with baseline $\leq 70 \mathrm{mmol} / \mathrm{mol}[-2.6 \mathrm{mmol} / \mathrm{mol}(95 \% \mathrm{CI}-3.8$ to -1.3$) ;-0.24 \%$ (95\% CI -0.35 to -0.12 ) 14-90 days after the start of dapagliflozin treatment (Fig. 3b). No differences were seen in the pattern of $\mathrm{HbA}_{1 \mathrm{c}}$ reductions when stratified by baseline BMI (Fig. 3c). 

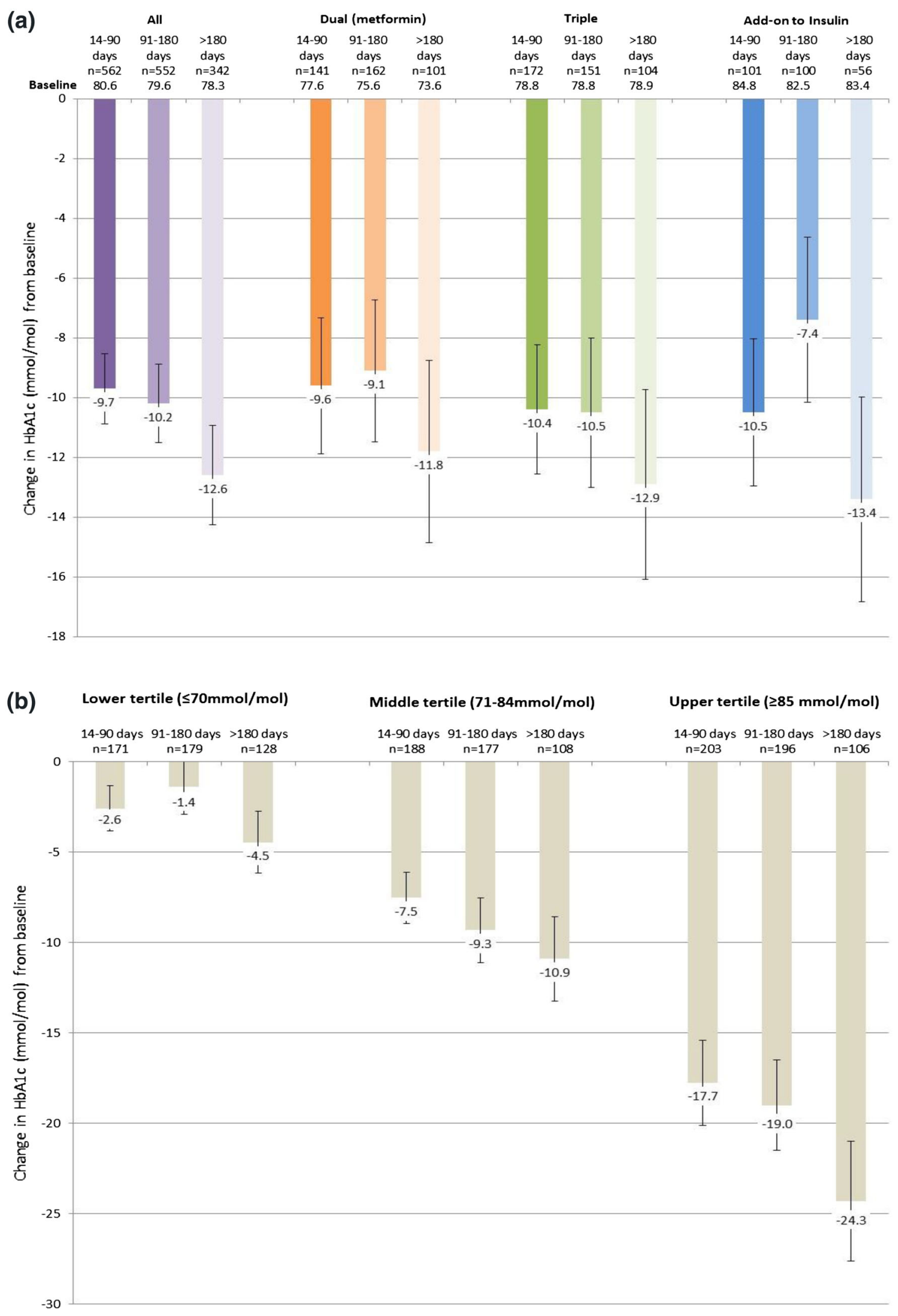


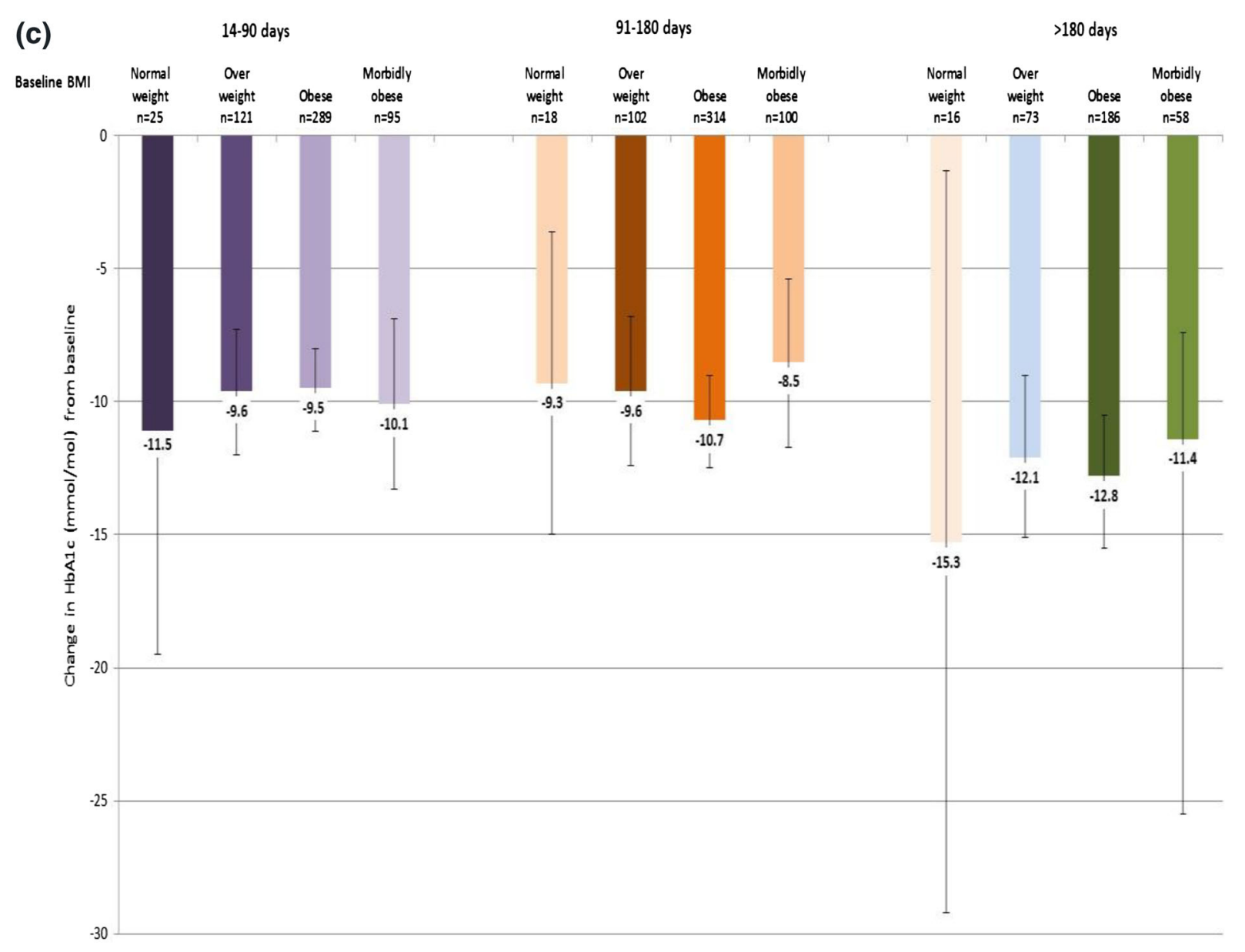

Fig. 3 continued

\section{Change in Body Weight Following Initiation of Dapagliflozin}

In patients with a recorded measurement, mean weight loss was $2.6 \mathrm{~kg}$ (95\% CI $2.3-2.9)$ 14-90 days after starting dapagliflozin, $4.3 \mathrm{~kg}$

4 Fig. 3 a Changes in glycated hemoglobin $(\mathrm{mmol} / \mathrm{mol})$ from baseline for each of the main treatment groups and the entire cohort for the three follow-up periods; error bars represent mean $\pm 95 \%$ confidence interval. b Changes in glycated hemoglobin $(\mathrm{mmol} / \mathrm{mol})$ from baseline by tertiles of baseline glycated hemoglobin for the three follow-up periods; error bars represent mean $\pm 95 \%$ confidence interval. c Changes in glycated hemoglobin $(\mathrm{mmol} / \mathrm{mol})$ from baseline by categories of baseline body mass index for the three follow-up periods; error bars represent mean $\pm 95 \%$ confidence interval
(95\% CI 3.8-4.7) after 91-180 days and $4.6 \mathrm{~kg}$ (95\% CI 4.0-5.2) beyond 180 days (Fig. 4; Supplementary material S4). This pattern of greater weight loss after longer treatment emerged in all subgroups stratified by treatment. Patients receiving dual therapy with metformin had a numerically greater reduction in weight, which was not statistically significant, than those who were receiving insulin.

\section{Change in Both $\mathrm{HbA}_{1 \mathrm{c}}$ and Body Weight Following Initiation of Dapagliflozin}

In patients with measurements between 91 and 180 days after starting dapagliflozin $(n=347)$, 


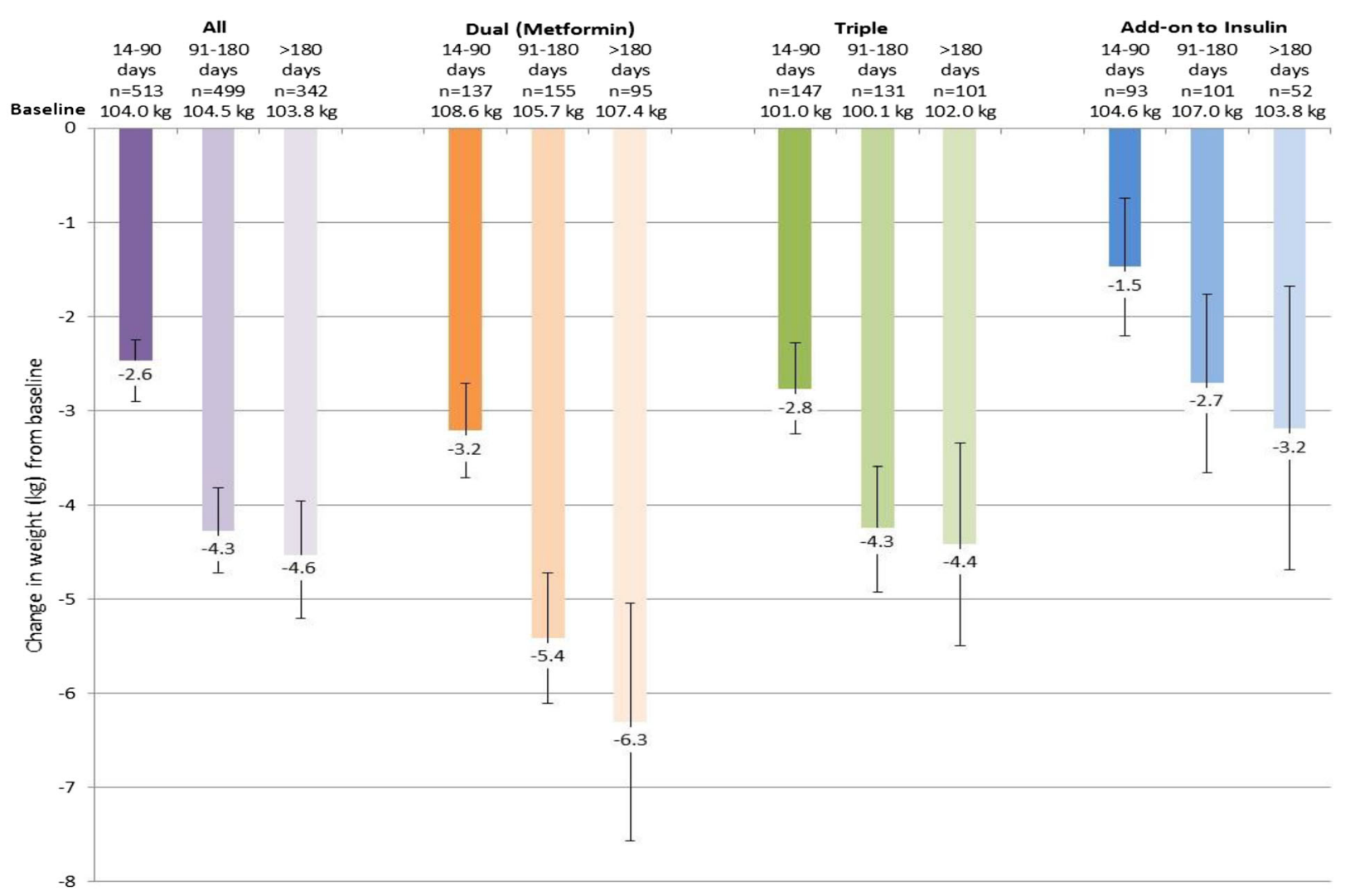

Fig. 4 Changes in body weight $(\mathrm{kg})$ from baseline for each of the main treatment groups and the entire cohort for the three follow-up periods; error bars represent mean $\pm 95 \%$ confidence interval

63.1\% had a decrease in both $\mathrm{HbA}_{1 \mathrm{c}}$ and weight, and only $3.2 \%$ had no decrease in either. Similar results were observed in patients who had follow-up beyond 180 days $(n=264), 68.2 \%$ had decreases in both $\mathrm{HbA}_{1 \mathrm{c}}$ and weight, and only $2.3 \%$ had no decrease in either.

Regression analysis shows that the odds of reaching an $\mathrm{HbA}_{1 \mathrm{c}}$ target of $\leq 58.5 \mathrm{mmol} / \mathrm{mol}(7.5 \%)$ is greatest in those with an $\mathrm{HbA}_{1 \mathrm{c}}<69.4 \mathrm{mmol} / \mathrm{mol}$ (8.5\%) at baseline (OR 12.63, CI 7.74-20.60; $p<0.0001$ ), intermediate with $\mathrm{HbA}_{1 \mathrm{c}} 69.4-85.8 \mathrm{mmol} / \mathrm{mol}$ (8.5-10.0\%) at baseline (OR 3.21, 95\% CI $1.94-5.32 ; \quad p<0.0001)$ compared to those with an $\mathrm{HbA}_{1 \mathrm{c}}>85.8 \mathrm{mmol} / \mathrm{mol} \quad(10 \%)$ (supplementary material S5).

Regression analysis also shows that the odds of reaching an $\mathrm{HbA}_{1 \mathrm{c}}$ target of $\leq 58.5 \mathrm{mmol} / \mathrm{mol}$
$(7.5 \%)$ is greatest in those who received dapagliflozin for 181 days or longer (OR 2.29, 95\% CI 1.26-4.14; $p<0.0063)$. Those with a baseline $\mathrm{HbA}_{1 \mathrm{c}}<69.4 \mathrm{mmol} / \mathrm{mol}$ (8.5\%) were also more likely to reach a target of $\leq 53.0 \mathrm{mmol} / \mathrm{mol} \quad(7.0 \%) \quad(\mathrm{OR} 9.95,95 \%$ CI 4.96-19.98; $p<0.0001)$ than those with an $\mathrm{HbA}_{1 \mathrm{c}}>85.8 \mathrm{mmol} / \mathrm{mol}(10 \%)$. Weight loss of $\geq 5 \%$ was more likely in those treated as dual therapy [OR with metformin (OR 2.41, 95\% CI 1.43-4.07; $p<0.0001)]$ compared with insulin treatment. Weight loss of $\geq 3 \%$ was also associated with dual metformin therapy (OR $2.55,95 \%$ CI $1.65-3.94 ; p<0.0001)$ and treatment for 91 days or more (OR 1.81, 95\% CI $1.35-2.42 ; \quad p<0.0001)$. Supplementary material S5 and S6 provides details of the regression analyses. 


\section{Change in Insulin Dose Following Initiation of Dapagliflozin}

In the 108 patients for whom sufficient questionnaire data were recorded to assess daily insulin dose at dapagliflozin initiation, $32(29.6 \%)$ patients received long-acting insulin only (mean 70.4 units, 95\% CI 52.1-88.7), one (0.9\%) patient received short-acting insulin only, and 75 (69.4\%) received short- and long-acting insulin either as a fixed mixture or in a basal-bolus regimen (mean 106.2 units, 95\% CI 90.6-121.8). The total average dose was 95.5 units (95\% CI 83.1-107.9).

Following initiation of dapagliflozin, no change in insulin dose was recorded for 36 patients (33.3\%), with 19 patients (17.6\%) having an increase in insulin dose and 53 (49.1\%) a decrease. In the 108 patients the average insulin dose decreased by 14.8 units (95\% CI 8.0-21.6) following dapagliflozin initiation. The average insulin dose decreased by 8.3 units (95\% CI 1.8-14.8) in patients with long-acting insulin and 17.8 units (95\% CI 8.4-27.2) in those with short-/long-acting insulin.

\section{Change in Blood Pressure Following Initiation of Dapagliflozin}

In patients with measurements between 14 and 90 days after starting dapagliflozin, systolic $(n=416) \quad$ and diastolic $(n=431)$ blood pressure decreased by means of 4.5 (95\% CI 3.2-5.8) $\mathrm{mmHg}$ and 2.0 (95\% CI 1.2-2.9), respectively from baseline. Similar reductions in systolic and diastolic blood pressure were observed after 91-180 days and when follow-up extended beyond 180 days (Supplementary material S7). In general, this pattern emerged in all subgroups stratified by treatment. After 180 days, however, the reductions in blood pressure were numerically smaller with dual and triple therapy than when dapagliflozin was added to insulin (Fig. 5a, b; Supplementary material S7).

\section{DISCUSSION}

In this observational study of patients with T2D initiated on dapagliflozin in primary care, patients had a similar age and duration of T2D to those in relevant clinical trials, but with worse baseline glycemic control and higher body weight. This pattern was seen throughout the three treatment groups: a BMI of 36.2 versus $31.2 \mathrm{~kg} / \mathrm{m}^{2}$ and mean baseline $\mathrm{HbA}_{1 \mathrm{c}}$ of $76.5 \mathrm{mmol} / \mathrm{mol}$ (9.15\%) versus $63.1 \mathrm{mmol} / \mathrm{mol}(7.92 \%)$ in patients prescribed dapagliflozin in combination with metformin (dual therapy) [1]; a BMI of 34.2 versus $32.0 \mathrm{~kg} /$ $\mathrm{m}^{2}$ and mean baseline $\mathrm{HbA}_{1 \mathrm{c}}$ of $78.8 \mathrm{mmol} / \mathrm{mol}$ (9.36\%) versus $66.6 \mathrm{mmol} / \mathrm{mol}$ (8.24\%) for patients receiving triple therapy [9]; and a BMI of 35.8 versus $33.4 \mathrm{~kg} / \mathrm{m}^{2}$ and mean baseline $\mathrm{HbA}_{1 \mathrm{c}}$ of $84.7 \mathrm{mmol} / \mathrm{mol} \quad(9.90 \%) \quad$ vs. $70.2 \mathrm{mmol} / \mathrm{mol}(8.57 \%)$ for patients who received dapagliflozin as add-on to insulin [10]. The basal and overall mean doses of insulin in the present study (66.9, 95.5 units, respectively) were higher than reported in the RCTs (32.0, 78.0 units, respectively) [11]. The reductions in $\mathrm{HbA}_{1 \mathrm{c}} \quad(9.7-12.6 \mathrm{mmol} / \mathrm{mol}$; $0.89-1.16 \%)$, weight $(2.6-4.6 \mathrm{~kg})$ and blood pressure (systolic $1.6-5.5 \mathrm{mmHg}$; diastolic $0.3-3.4 \mathrm{mmHg}$ ) after addition of dapagliflozin in the present study were broadly consistent with results from the dapagliflozin clinical trial programme [1, 4-8, 10, 11].

Although an observational study population will not map exactly to any RCT, there are clinical trials in which patients were treated with similar combinations of therapy to the 


\begin{tabular}{|c|c|c|c|c|c|c|c|c|c|c|c|c|}
\hline \multirow{2}{*}{ (a) } & \multicolumn{3}{|c|}{ All } & \multicolumn{3}{|c|}{ Dual (Metformin) } & \multicolumn{3}{|c|}{ Triple } & \multicolumn{3}{|c|}{ Add-on to Insulin } \\
\hline & $\begin{array}{c}14-90 \\
\text { days } \\
\mathrm{n}=416\end{array}$ & $\begin{array}{c}91-180 \\
\text { days } \\
n=398\end{array}$ & $\begin{array}{c}>180 \\
\text { days } \\
\mathrm{n}=304\end{array}$ & $\begin{array}{c}14-90 \\
\text { days } \\
n=104\end{array}$ & $\begin{array}{c}91-180 \\
\text { days } \\
n=114\end{array}$ & $\begin{array}{l}>180 \\
\text { days } \\
n=83\end{array}$ & $\begin{array}{c}14-90 \\
\text { days } \\
\mathrm{n}=117\end{array}$ & $\begin{array}{c}91-180 \\
\text { days } \\
n=110\end{array}$ & $\begin{array}{l}>180 \\
\text { days } \\
n=87\end{array}$ & $\begin{array}{c}14-90 \\
\text { days } \\
\end{array}$ & $\begin{array}{c}91-180 \\
\text { days }\end{array}$ & $\begin{array}{l}>180 \\
\text { days }\end{array}$ \\
\hline $\begin{array}{l}\text { Baseline } \\
(\mathrm{mm} / \mathrm{Hg})\end{array}$ & $\begin{array}{c}n=416 \\
135.8\end{array}$ & $\begin{array}{l}n=398 \\
134.0\end{array}$ & $\begin{array}{c}n=304 \\
133.1\end{array}$ & $\begin{array}{c}n=104 \\
136.5\end{array}$ & $\begin{array}{c}n=114 \\
135.1\end{array}$ & $\begin{array}{l}n=83 \\
134.4\end{array}$ & $\begin{array}{l}n=117 \\
136.0\end{array}$ & $\begin{array}{l}n=110 \\
132.1\end{array}$ & $\begin{array}{l}n=87 \\
132.3\end{array}$ & $\begin{array}{c}n=83 \\
136.1\end{array}$ & $\begin{array}{l}n=84 \\
135.0\end{array}$ & $\begin{array}{l}n=51 \\
132.4\end{array}$ \\
\hline
\end{tabular}

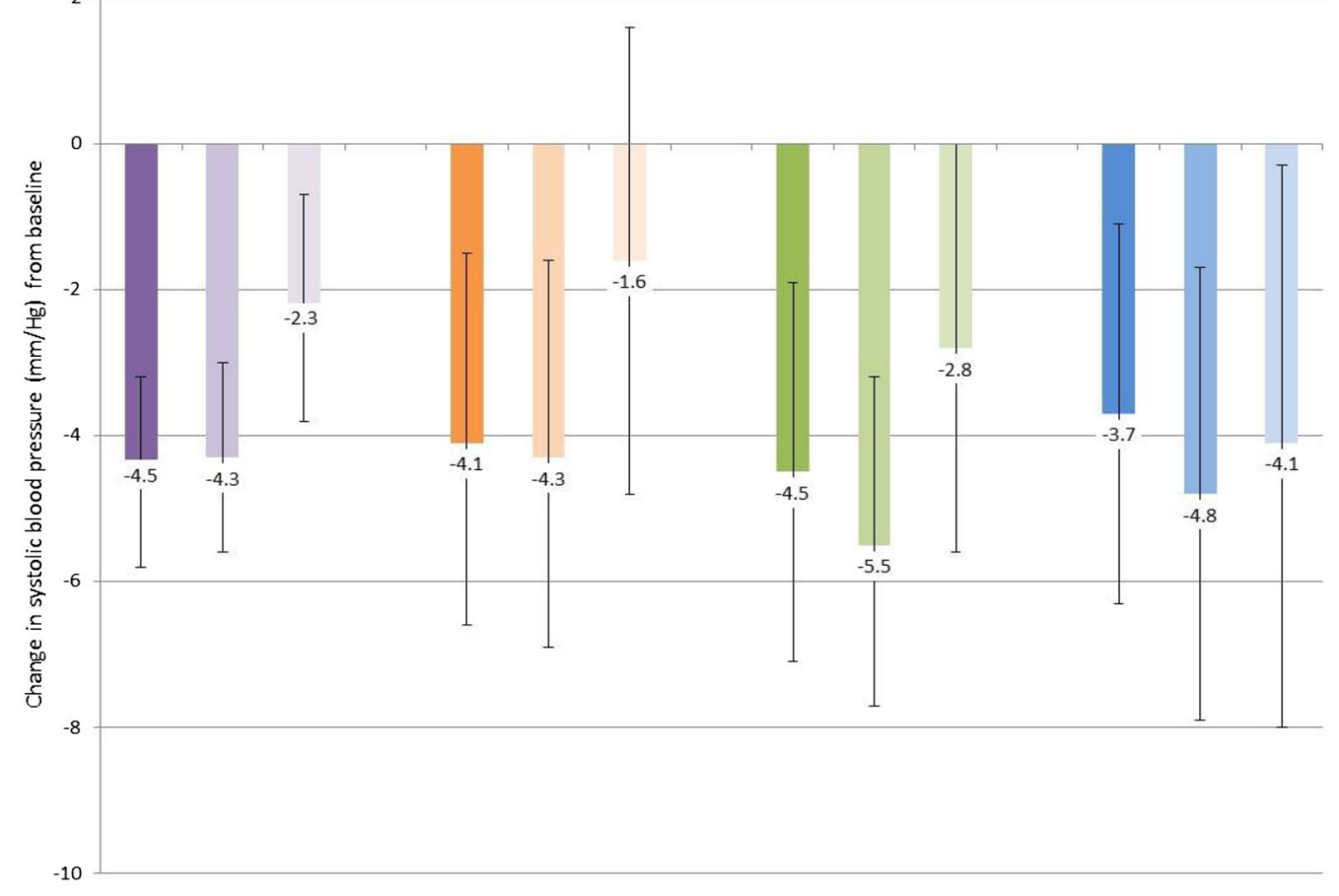

(b) Lower tertile (<129 mm/Hg)

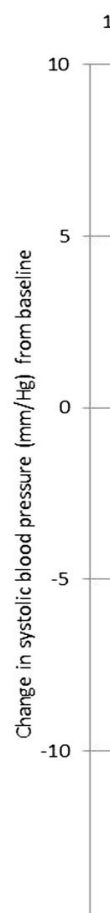

$\begin{array}{cc}14-90 \text { days } & 91-180 \text { days } \\ n=122 & >180 \text { days } \\ n=122 & n=96\end{array}$

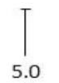
5.0
Middle tertile $(130-139 \mathrm{~mm} / \mathrm{Hg})$

14-90 days $91-180$ days $>180$ days $n=116 \quad n=127 \quad n=107$

Upper tertile ( $\geq 140 \mathrm{~mm} / \mathrm{Hg}$ )

$\begin{array}{rl} & 14-90 \text { days } \\ n=96 & n=116\end{array}$

$-15$
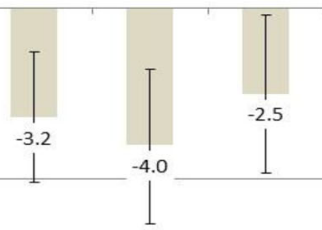
4Fig. 5 a Changes in blood pressure $(\mathrm{mmHg})$ from baseline for each of the main treatment groups and the entire cohort for the three follow-up periods; error bars represent mean $\pm 95 \%$ confidence interval. b Changes in blood pressure stratified by baseline blood pressure; for the three follow-up periods; error bars represent mean $\pm 95 \%$ confidence interval

most common treatment groups in our study. First, for example, in patients treated with metformin ( $\geq 1500 \mathrm{mg}$ per day), add-on of dapagliflozin (10 mg) reduced $\mathrm{HbA}_{1 \mathrm{c}}$ by $8.7 \mathrm{mmol} / \mathrm{mol}$ (unadjusted difference) (0.79\%) compared with $3.2 \mathrm{mmol} / \mathrm{mol}(0.30 \%)$ with placebo after 24 weeks [1]. Second, in a controlled trial, patients treated with dapagliflozin added to metformin plus sulfonylurea showed a placebo-subtracted reduction in $\mathrm{HbA}_{1 \mathrm{c}}$ of $7.5 \mathrm{mmol} / \mathrm{mol}(0.69 \%)$ after 24 weeks [9]. Third, T2D patients who were inadequately controlled by insulin with or without other oral glucose-lowering drugs and who received dapagliflozin, mean $\mathrm{HbA}_{1 \mathrm{c}}$ reductions at week 24 were $10.5 \mathrm{mmol} / \mathrm{mol}$ $(0.96 \%)$ with dapagliflozin $10 \mathrm{mg}$ versus $4.3 \mathrm{mmol} / \mathrm{mol}(0.39 \%)$ with placebo [11]. The reductions in $\mathrm{HbA}_{1 \mathrm{c}}$ were similar in the present study, which confirms the consistency of effects of dapagliflozin in trial and the real world use.

The numerically greater decreases in $\mathrm{HbA}_{1 \mathrm{c}}$ observed in this real-world evidence study could be explained in part by the higher baseline values, this is consistently seen in most trials of glucose-lowering treatments, irrespective of the treatment used $[1,3,9,14]$. The reasons in this dataset may relate in part to greater glucosuria at higher blood glucose levels and statistical effects such as regression to the mean, although the precise cause is not fully understood. Reductions in $\mathrm{HbA}_{1 \mathrm{c}}$ recorded after a longer treatment with dapagliflozin were generally larger than those recorded earlier in the course of treatment, which again is consistent with long-term controlled trials [5]. However, the regression analysis shows that those patients with lower $\mathrm{HbA}_{1 \mathrm{c}}$ values before treatment were more likely to reach targets of $\leq 58.5 \mathrm{mmol} / \mathrm{mol}$ $(7.5 \%)$ and $\leq 53.0 \mathrm{mmol} / \mathrm{mol}(7 \%)$ than those with very high values. In addition, the regression analysis suggested treatment for 181 days and longer was more likely to be associated with the achievement of $\mathrm{HbA}_{1 \mathrm{c}}$ targets of $\leq 58.5 \mathrm{mmol} / \mathrm{mol}$ (7.5\%), but might also reflect a bias where patients who are responding well are more likely to persist with treatment. Older patients and those with very long duration diabetes seemed less likely to have a good $\mathrm{HbA}_{1 \mathrm{c}}$ response. This might reflect renal function, which declines with age and duration of diabetes. However, renal function was not assessed in the regression analysis.

In clinical trials, significant weight reductions of $1.5-2.1 \mathrm{~kg}$ (placebo subtracted) have been reported in patients treated with dapagliflozin (10 mg) as add-on to metformin with or without sulphonylurea or insulin over 24 weeks [1, 9, 11]. In longer studies, weight appeared to stabilize after 24 weeks $[4,11]$. The present study observed weight reductions of $5.4 \mathrm{~kg}$ (add-on to metformin), $4.3 \mathrm{~kg}$ (triple therapy) and $2.7 \mathrm{~kg}$ (add-on to insulin) at 3-6 months and greater reductions in patients treated beyond 6 months $(6.3,4.4$ and $3.2 \mathrm{~kg}$, respectively), numerically greater than those seen in the RCT. This might be influenced by the relatively high baseline values in our study: McGovern et al. showed that a higher BMI at baseline was associated with greater weight loss [15]. In this study, BMI at baseline was not associated with weight loss. However, weight loss of $\geq 3$ and $\geq 5 \%$ was associated with treatment with dapagliflozin for 91 days or longer, and with dual therapy with dapagliflozin and metformin. 
Hypertension is common in T2D patients and further increases the risk of micro vascular and macro vascular complications [16]. The reductions in BP associated with dapagliflozin in the present study (systolic 1.6-5.5 $\mathrm{mmHg}$; diastolic $0.3-3.4 \mathrm{mmHg}$ ) are similar in the entire population and in subgroups stratified by treatment. The findings are broadly consistent with other studies. Weber et al. assessed dapagliflozin in patients with uncontrolled T2D and hypertension. Dapagliflozin was associated with greater reductions in systolic blood pressure compared to placebo (adjusted mean change from baseline -11.90 and $-7.62 \mathrm{mmHg}$, respectively; placebo-adjusted difference $4.28 \mathrm{mmHg}$ ) [16]. The smaller reduction in the present study presumably reflects the population, of whom only $58 \%$ had hypertension.

The median duration of therapy in this study was 10.8 months, consistent with an acceptable tolerability profile; however, no data were collected on tolerability. In a previous clinical study, $15.4 \%$ of patients receiving dapagliflozin (10 $\mathrm{mg}$ daily) added to metformin and $4.4 \%$ of those taking placebo and metformin discontinued due to adverse events during 102 weeks' treatment [5]. An observational hospital study reported that $22 \%$ of patients discontinued dapagliflozin due to side effects and $52 \%$ stopped or reduced the dose of at least one other diabetes medication [15].

Whereas limited external validity compromises many large trials of glycemic control among T2D patients [12], the CPRD database captures a representative sample of the UK population of over 12 million people [13] from 680 general practices. The present alignment of data from our observational study with those from RCT suggests that the findings are robust and could be generalized to a
UK primary care population. The effects of dapagliflozin initiation in secondary hospital care settings were assessed by a small observational study by McGovern et al. in 96 T2D patients, $42 \%$ of their population showed a reduction of $\geq 1 \%$ in $\mathrm{HbA}_{1 \mathrm{c}}, 15 \%$ showed weight loss $\geq 5 \mathrm{~kg}$ and $3 \%$ showed weight loss $\geq 10 \mathrm{~kg}$ [15]. These improvements in $\mathrm{HbA}_{1 \mathrm{c}}$, weight and blood pressure were consistent with those reported in clinical trials [15].

The present results confirm the multiple patient factors beyond poor glycemic control per se that contribute to the decision to prescribe dapagliflozin to insulin-treated patients, particularly insulin resistance, avoidance of weight gain and hypoglycemia.

Our study is associated with several limitations, largely reflecting the source of the data. For example, clinicians may vary in the time since last $\mathrm{HbA}_{1 \mathrm{c}}$ measurement when they move patients to the next treatment step, the detail with which they complete clinical measures and the information added to the records. There is evidence from a systematic review that $15-33 \%$ of diabetes patients are non-adherent with oral glucose-lowering therapy [17]. However, as CPRD records that a prescription was issued, not whether it was dispensed or taken by the patient, we are unable to assess adherence in our population. It is likely that the results reported were achieved despite potentially higher levels of non-adherence compared with an RCT population. In addition, CPRD does not capture medicines prescribed in secondary care. Therefore, the first dapagliflozin prescription entered in CPRD may not be the first time the patient received the drug. This would tend to underestimate changes in $\mathrm{HbA}_{1 \mathrm{c}}$ and weight associated with dapagliflozin in primary care. The results of the GP questionnaire might be subject to selection and recollection bias, 
especially if the reasons for adding dapagliflozin are not clearly documented in the notes. Since this is a descriptive study without a comparative arm, any changes observed may not relate to dapagliflozin alone. As such, the results must be regarded as hypothesis generating although they are consistent with the Phase 3 clinical evidence. Because this analysis is mostly concerned with the initial year of treatment with dapagliflozin, it is not possible from these data to predict therapeutic persistence.

Finally, another limitation of this study is that adverse events were not examined. Adverse events like hypoglycemia are likely to be underestimated in a primary care database due to missing detailed clinical information. We would need to examine anonymized free text entered by the GP or send out questionnaires to GPs. Free text has not been available in CPRD since mid-2013 and approximately $90 \%$ of our cohort initiated dapagliflozin after June 2013. Furthermore, most patients not on insulin are not advised to self-monitor blood glucose so may not detect minor hypoglycemic episodes if they occur. Many hypoglycemic episodes are treated by ambulance crews without hospital admission and this information is not captured in the GP record [18]. The majority of patients in this study were not prescribed insulin. Secondary care data would be required to identify severe hypoglycemic events leading to hospitalizations. Although, CPRD primary care data can be linked to secondary care data, there is incomplete linkage and a lag in follow-up. The lag in follow-up is a particular problem when examining medications which have a relatively recent launch date like dapagliflozin. Rates of hypoglycemia in RCTs when dapagliflozin was added to metformin or used as monotherapy were similar to placebo [1]; and over 2 years there was also no difference when used in combination with insulin [19].

\section{CONCLUSION}

This first observational study in patients treated with dapagliflozin in primary care practice in the UK found that $\mathrm{HbA}_{1 \mathrm{c}}$ weight and blood pressure were reduced after initiation of dapagliflozin, and this is consistent with results from the dapagliflozin clinical trial programme.

\section{ACKNOWLEDGMENTS}

Sponsorship and article processing charges for this study were funded by AstraZeneca. The authors acknowledge the medical writing assistance from Mark Greener, at Omega Scientific, funded by AstraZeneca. We also thank Muriel De Vos, Medical Affairs Manager of AstraZeneca, for editorial support. All the authors had access to all the data and analyses. All named authors meet the International Committee of Medical Journal Editors (ICMJE) criteria for authorship for this manuscript, take responsibility for the integrity of the work as a whole, and have given final approval for the version to be published.

Disclosures. J. Wilding has served as a consultant for AstraZeneca, Boehringer Ingelheim, Bristol-Myers Squibb, Janssen, Novo Nordisk and Orexigen; he has served as a speaker for AstraZeneca, Bristol-Myers Squibb, Janssen, Eli Lilly, Novo Nordisk and Takeda; and he has received research support from AstraZeneca, Eli Lilly, Novo Nordisk and Takeda. C. Bailey has served as a consultant for AstraZeneca, Boehringer Ingelheim/Lilly, Bristol-Myers Squibb, MSD, Janssen, Novo Nordisk, Sanofi and Takeda. U. Rigney is an employee of AstraZeneca. B. Blak is an employee of AstraZeneca. W. Beekman is an employee of 
AstraZeneca. C. Emmas is an employee of AstraZeneca.

Compliance with Ethics Guidelines. This was an observational, retrospective study using anonymised data from CPRD, which holds ethical approval for observational studies. The Independent Scientific Advisory Committee for Medicines and Healthcare products Regulatory Agency (Protocol Number 14_236AMn) approved this study. This article is based on observational data and does not involve any new studies of human or animal subjects performed by any of the authors.

Open Access. This article is distributed under the terms of the Creative Commons Attribution-NonCommercial 4.0 International License (http://creativecommons.org/licenses/ by-nc/4.0/), which permits any noncommercial use, distribution, and reproduction in any medium, provided you give appropriate credit to the original author(s) and the source, provide a link to the Creative Commons license, and indicate if changes were made.

\section{REFERENCES}

1. Bailey C, Gross J, Pieters A, Bastien A, List J. Effect of dapagliflozin in patients with type 2 diabetes who have inadequate glycaemic control with metformin: a randomised, double-blind, placebo-controlled trial. Lancet. 2010;375:2223-33.

2. Bailey CJ, Iqbal N, T'joen C, List JF. Dapagliflozin monotherapy in drug-naïve patients with diabetes: a randomized-controlled trial of low-dose range. Diabetes Obes Metab. 2012;14:951-9.

3. Ferrannini E, Ramos SJ, Salsali A, Tang W, List JF. Dapagliflozin monotherapy in type 2 diabetic patients with inadequate glycemic control by diet and exercise: a randomized, double-blind, placebo-controlled, phase 3 trial. Diabetes Care. 2010;33:2217-24.
4. Bailey CJ, Gross JL, Hennicken D, Iqbal N, Mansfield TA, List JF. Dapagliflozin add-on to metformin in type 2 diabetes inadequately controlled with metformin: a randomized, double-blind, placebo-controlled 102-week trial. BMC Med. 2013;11:43.

5. Bolinder J, Ljunggren Ö, Johansson L, et al. Dapagliflozin maintains glycaemic control while reducing weight and body fat mass over 2 years in patients with type 2 diabetes mellitus inadequately controlled on metformin. Diabetes Obes Metab. 2014;16:159-69.

6. Nauck MA, Del Prato S, Meier JJ, et al. Dapagliflozin versus glipizide as add-on therapy in patients with type 2 diabetes who have inadequate glycemic control with metformin: a randomized, 52-week, double-blind, active-controlled noninferiority trial. Diabetes Care. 2011;34:2015-22.

7. Jabbour SA, Hardy E, Sugg J, Parikh S; for the Study 10 Group. Dapagliflozin is effective as add-on therapy to sitagliptin with or without metformin: a 24-week, multicenter, randomized, double-Blind, placebo-controlled study. Diabetes Care. 2014;37:740-50.

8. Strojek K, Yoon KH, Hruba V, Elze M, Langkilde AM, Parikh S. Effect of dapagliflozin in patients with type 2 diabetes who have inadequate glycaemic control with glimepiride: a randomized, 24-week, double-blind, placebo-controlled trial. Diabetes Obes Metab. 2011;13:928-38.

9. Matthaei S, Bowering K, Rohwedder K, Grohl A, Parikh S, Study 05 Group. Dapagliflozin improves glycemic control and reduces body weight as add-on therapy to metformin plus sulfonylurea: a 24-week randomized, double-blind clinical trial. Diabetes Care. 2015;38:365-72.

10. Wilding JPH, Norwood P, T'joen C, Bastien A, List JF, Fiedorek FT. A study of dapagliflozin in patients with type 2 diabetes receiving high doses of insulin plus insulin sensitizers: applicability of a novel insulin-independent treatment. Diabetes Care. 2009;32:1656-62.

11. Wilding JPH, Woo V, Soler NG, et al. Long-term efficacy of dapagliflozin in patients with type 2 diabetes mellitus receiving high doses of insulin: a randomized trial. Ann Intern Med. 2012;156:405-15.

12. Saunders C, Byrne CD, Guthrie B, et al. External validity of randomized controlled trials of glycaemic control and vascular disease: how representative are participants? Diabet Med. 2013;30:300-8. 
13. Williams T, van Staa T, Puri S, Eaton S. Recent advances in the utility and use of the General Practice Research Database as an example of a UK Primary Care Data resource. Ther Adv Drug Saf. 2012;3:89-99.

14. Bloomgarden ZT, Dodis R, Viscoli CM, Holmboe ES, Inzucchi SE. Lower baseline glycemia reduces apparent oral agent glucose-lowering efficacy. Diabetes Care. 2006;29(9):2137-9.

15. McGovern A, Dutta N, Munro N, Watters K, Feher M. Dapagliflozin: clinical practice compared with pre-registration trial data. Br J Diabetes Vasc Dis. 2014;14:138-43.

16. Weber MA, Mansfield TA, Cain VA, Iqbal N, Parikh S, Ptaszynska A. Blood pressure and glycaemic effects of dapagliflozin versus placebo in patients with type 2 diabetes on combination antihypertensive therapy: a randomised, double-blind, placebo-controlled, phase 3 study. Lancet Diabetes Endocrinol. 2016;4:211-20.

17. Cramer JA. A systematic review of adherence with medications for diabetes. Diabetes Care. 2004;27:1218-24.

18. Elwen FR, Huskinson A, Clapham L, Bottomley MJ, Heller SR, James C, Abbas A, Baxter P, Ajjan RA. An observational study of patient characteristics and mortality following hypoglycemia in the community. BMJ Open Diabetes Res Care. 2015;3:e000094. doi:10.1136/bmjdrc-2015-000094.

19. Wilding JPH, Woo V, Rohwedder K, Sugg J, Parikh S. Dapagliflozin in patients with type 2 diabetes receiving high doses of insulin: efficacy and safety over 2 years. Diabetes Obes Metab. 2014;16(2):124-36. 